\title{
Design and Fabrication of Automatic Dosa Maker
}

\author{
Ajay Krishna, Akash.V.M, Akhil.S, Dhanushma Prathap, Bindu.S.S
}

\begin{abstract}
Dosa is a traditional food common in South Indian homes. It has been an integral part of South Indian breakfast since ages. Dosa is usually cooked with a non-stick pan and spatula which is time consuming and needs continuous attention of the cook. As the value of time is increasing day by day, especially with the increase in working women, the demand for ready-to-eat traditional food is also increasing. Different prototype developments for Dosa Maker have been conducted widely. Automation plays an important role in the food sector. Automation reduces cycle time, limits human interference hence increasing productivity. The main problem that arises during the design of Dosa maker is to bake both sides of the Dosa automatically. The present work mainly focuses on design, development and fabrication of a fully Automatic Dosa Maker enabled to bake both sides of Dosa without any manual help. A programmed Arduino Mega is used to control the working of the entire system. A servomotor is used here, which helps to flip the Dosa in order to bake both the sides thus enabling to make tasty and hygienic Dosas. The Automatic Dosa Maker is a user friendly and portable machine. As the whole device works on its own it is easy to operate. The whole device runs on electric power. Using electricity as a source of power has less impact on the environment compared to the conventionally used petroleum gas.

Keyword : Automatic, Dosa, Fermented batter, Flipping arm
\end{abstract}

\section{INTRODUCTION}

Dosa is a traditional food item commonly used in south Indian homes. It is a rice pancake originating from South India, made from fermented batter which consists of main ingredients such as rice and black gram, soaked and ground together to a smooth batter generally in $3: 1$ or $4: 1[1]$ proportion with a dash of salt. The fermented batter is mixed with water to get the desired consistency. Traditionally, Dosa is served with a bowl of sambar, coconut chutney and spicy tomato chutney along with the other accompaniments. Dosa was already in use in the ancient Tamil country around the 1st century AD. Since time immemorial fermented foodstuffs are an important part of the diets of many parts of the population because of their benefits in providing high nutritive value, better organoleptic characteristics, shorter cooking time, prolonged shelf life and enhancement of flavor and aroma in foods.

Revised Manuscript Received on June 15, 2020.

* Correspondence Author

Bindu.S.S*, Department of Mechanical Engineering, Rajadhani Institute of Science and Technology, Thiruvananthapuram, India. Email: binduss@rietedu.in

Akash.V.M, Department of Mechanical Engineering, Rajadhani Institute of Science and Technology, Thiruvananthapuram, India. Email: akashvijay1997@gmail.com

Akhil.S, Department of Mechanical Engineering, Rajadhani Institute of Science and Technology, Thiruvananthapuram, India. Email: akhilsnairmuthana@gmail.com

Dhanushma Prathap, Department of Mechanical Engineering, Rajadhani Institute of Science and Technology, Thiruvananthapuram, India. Email: dhanushmaprathap@gmail.com

Ajay Krishna, Department of Mechanical Engineering, Rajadhani Institute of Science and Technology, Thiruvananthapuram, India. Email: ajaykrishna8642@gmail.com

(c) The Authors. Published by Blue Eyes Intelligence Engineering and Sciences Publication (BEIESP). This is an open access article under the CC BY-NC-ND license (http://creativecommons.org/licenses/by-nc-nd/4.0/)
One plain Dosa without oil contains about 112 calories[10], of which $82 \%$ is carbohydrate and $16 \%$ protein and $2 \%$ fat.You can also use other healthy ingredients instead of rice such as oats or rawa to alter the taste and calorie count of Dosa. The fermentation process of batter increases the vitamin $\mathrm{B}$, vitamin $\mathrm{C}$ and decreases the phytate (the hard to digest component of legumes) content. The microorganisms responsible for the fermentation are naturally present in the ingredients of Dosa batter (the rice and black gram), some of them are provided by water and air. These microorganisms are multiplied during the soaking process, then again during the resting process after grinding. A temperature of $25^{\circ}-30^{\circ} \mathrm{C}[9]$ is found to be highly favorable for the microorganisms to boost the fermentation process. Dosa batter can be stored for as long as 1 week or even more, if it is not fermented. Already fermented Dosa batter will stay good for about 3-4 days[1]. As a food product - easy digestibility, good nutritive value and easiness to make contributes to the increasing popularity of Dosa in all parts of India and also in other countries.

\subsection{Objective}

- The main aim of this work is to conceptualize, design and fabricate a fully functional automated

- Dosa making machine which bakes both the sides of the Dosa.

- It makes Dosas automatically at the press of a button without the need for human intervention in its cycle of operation.

- Human workforce is eliminated in every possible situation in the present scenario. This makes what is usually a daily activity an effortless task that doesn't require your attention.

- Another advantage is the drastic decrease in cost as compared to other machines similar to its kind.

\section{METHODOLOGY}

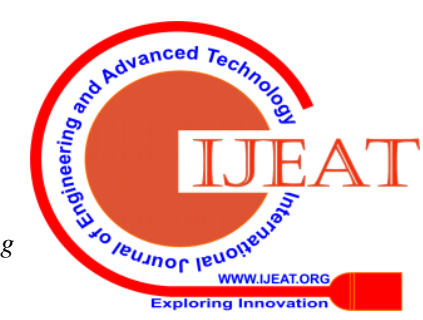


Design and Fabrication of Automatic Dosa Maker

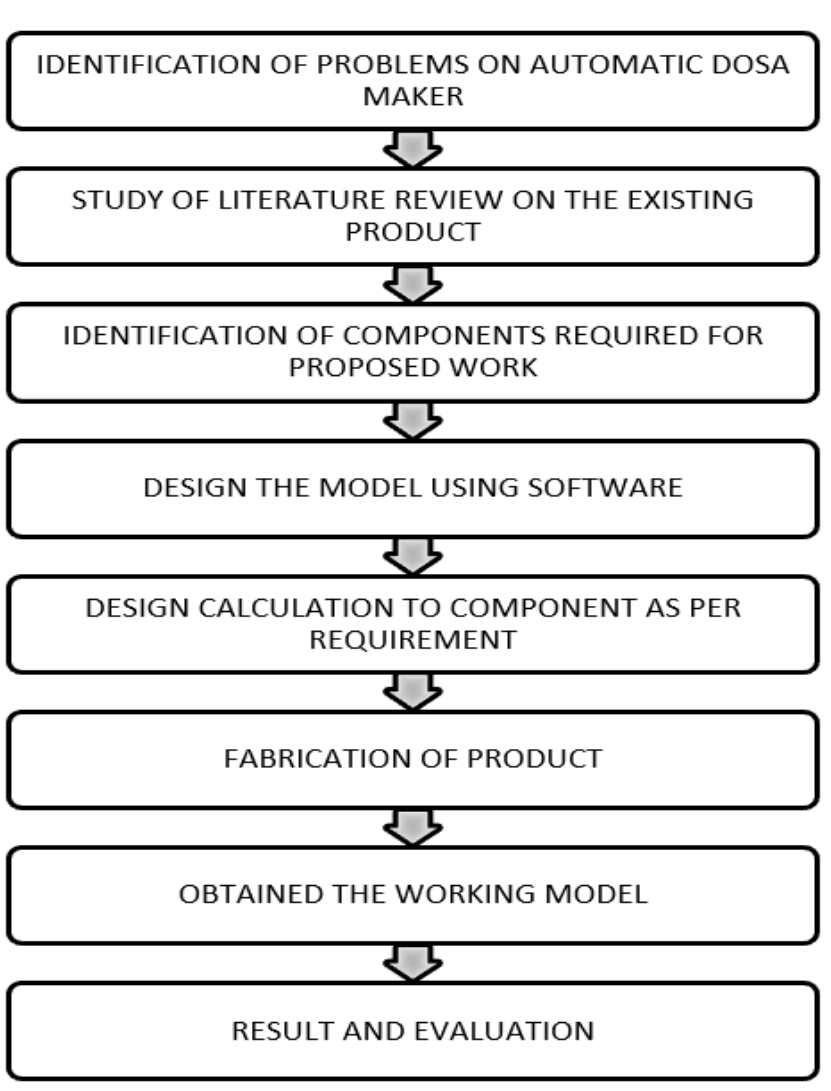

Fig 2.1 Methodology

\section{COMPONENTS AND SPECIFICATIONS}

\begin{tabular}{|c|c|c|}
\hline Components & Photograph & Specifications \\
\hline $\begin{array}{l}\text { Arduino } \\
\text { Mega }\end{array}$ & 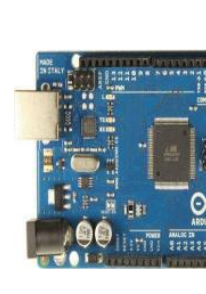 & $\begin{array}{l}\text { Operating } \\
\text { Voltage } \\
=5 \mathrm{~V} \\
\text { Input Voltage } \\
=7-12 \mathrm{~V} \\
\text { Clock Speed } \\
=16 \mathrm{MHz}\end{array}$ \\
\hline $\begin{array}{l}12 \mathrm{~V} 10 \mathrm{~A} \\
\text { SMPS }\end{array}$ & & $\begin{array}{l}\text { Item model no. } \\
=12 \mathrm{~V} 10 \mathrm{~A} \\
\text { Input Voltage } \\
=\mathrm{AC} 90-264 \mathrm{~V} \\
\text { Output Voltage } \\
=12 \mathrm{~V} \text { DC, } 10 \mathrm{~A} \\
\text { Wattage } \\
=120 \text { Watts }\end{array}$ \\
\hline Servo Motor & & $\begin{array}{l}\text { Model } \\
=\text { MG995 } \\
\text { Operating } \\
\text { Voltage } \\
=4.8 \mathrm{~V}-7.2 \mathrm{~V} \\
\text { Operating } \\
\text { Speed at } 4.8 \mathrm{~V} \\
=0.20 \mathrm{sec} / 60^{\circ}\end{array}$ \\
\hline
\end{tabular}

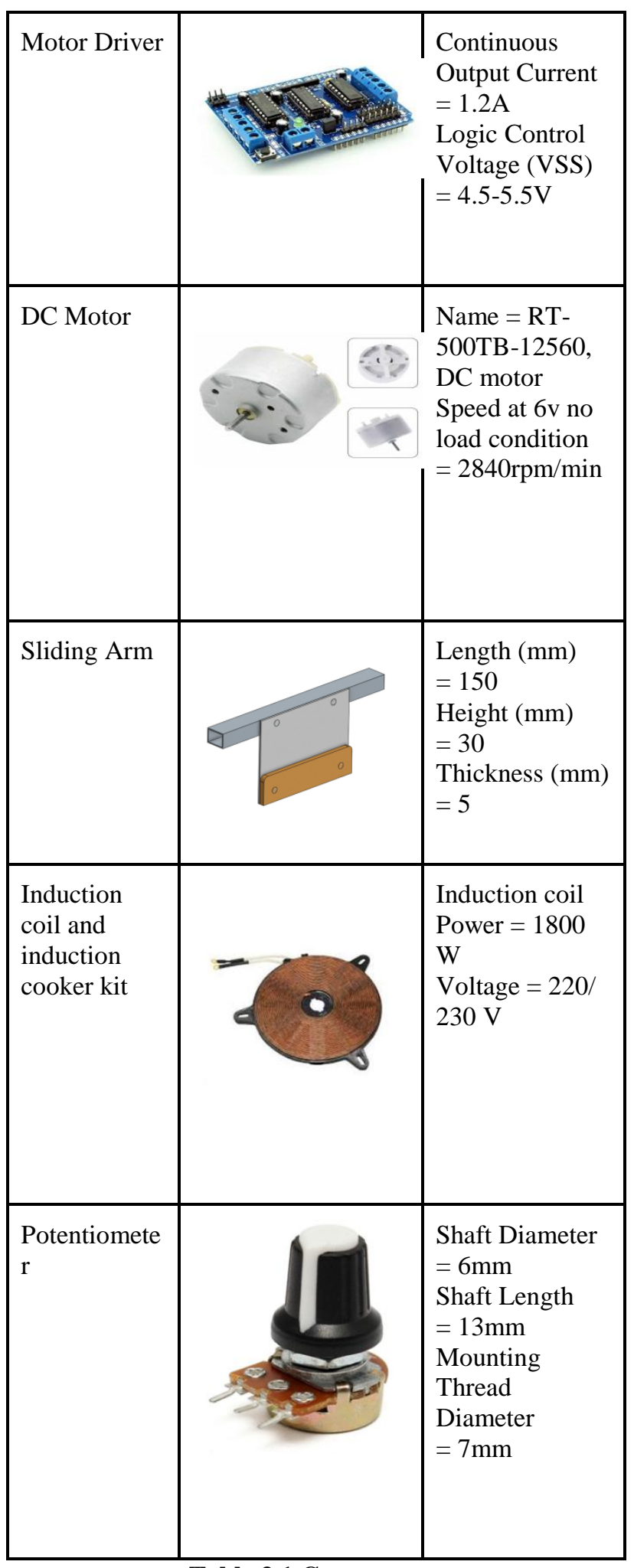

Table 3.1 Components

Published By:

Blue Eyes Intelligence Engineering

\& Sciences Publication

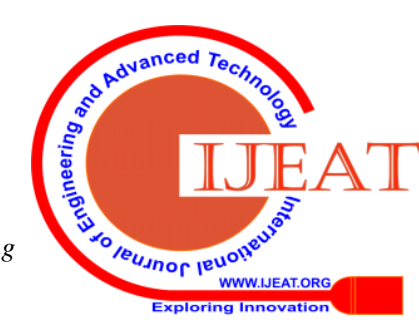


IV.

MECHANISM

Connections to the main supply

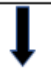

Adjustment of the baking temperature

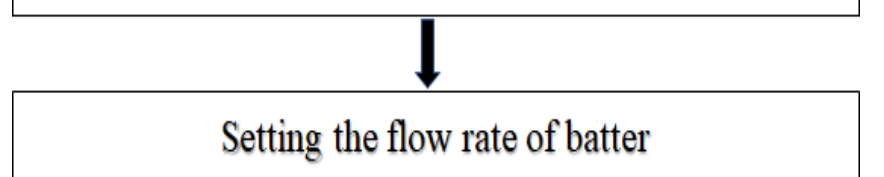

Flow of batter from the storage container to cooking

m

Adjusting the baking time period

One side baking of Dosa to the pre-set time

Movable arm slides away the half baked Dosa to flipping plate

The flipping plate moves upward and rotate itself to an angle of 70 degree

The unbaked side of Dosa is now on the cooking pan

The Dosa is now baked completely

Dosa again moved to the flip plate by movable arm

\section{From the flip plate cooked Dosa is now served to plate}

Fig 4.1 Mechanism

The power pins of induction cooktop and SMPS are connected to the main power supply separately. From SMPS, power is supplied to Arduino Mega [2] [8] through a voltage regulator. The temperature is adjusted on the induction cooktop. The oil is applied on top of the cooking pan surface to avoid sticking, by a movable sliding arm which travels from left extreme position to right extreme position. The position of the sliding arm is sensed by Arduino Mega by taking the values of switches $S_{1}$ and $S_{2}$.
At the left extreme position, switch $\mathrm{S}_{1}$ will be $\mathrm{ON}$ and switch $S_{2}$ will be OFF which corresponds to value $(0,1)$ and at right extreme position value will be $(1,0)$. Arduino Mega controls the DC motor through a motor driver [2] circuit. A lead screw is driven by the DC motor $\mathrm{M}_{1}$. Rotary motion of lead screw is converted to linear motion of the sliding arm by nut and screw mechanism. The quantity of batter and baking time are varied through two individual control knobs $K_{1}$ and $K_{2}$ which sets values for - time for which solenoid valve [4] remains open and time for baking one side of Dosa respectively. Both the control knobs are connected to two potentiometers respectively. The potentiometers are connected to the analog pins of Arduino Mega[2]. As the control knobs are adjusted, the resistance in potentiometers varies thus leading to variation in current flow. This variation in current is taken as input signal to the Arduino Mega through an analog to digital converter. A value between 0 to 3 seconds is assigned for $K_{1}$ and a value between 30 seconds to 2 minute is assigned to $\mathrm{K}_{2}$. Based on the time assigned to $K_{1}$ Arduino Mega controls the solenoid valve through a relay. When the relay is turned ON, current from SMPS reaches the solenoid valve and activates it. Dosa batter from the storage container [7] flows to the cooking pan. After the batter is baked to the pre-set time [6] assigned to $\mathrm{K}_{2}$, the sliding arm moves from left extreme to right extreme. As the sliding arm moves, it slides away the one side baked Dosa to the flipping plate. As the Arduino Mega senses the presence of the sliding arm at the right extreme end $\left(S_{1}, S_{2}=1,0\right)$, the arm is called back to the left extreme by programming in Arduino Mega. The DC motor runs in the opposite direction and the sliding arm reaches the left extreme end. The flipping plate is now at the lowest position and switches $S_{3}$ and $S_{4}$ are in ON condition i.e., 0 values for both switches. The flipping plate arms are rotated by DC motors $\mathrm{M}_{2}$ and $\mathrm{M}_{3}$. As the flipping plate arms move upwards, the flipping plate maintains a balanced horizontal position with the help of a servo motor. The flipping plate arms now reach the limit switches $S_{5}$ and $S_{6}$ at the top position whose values now change from 1 to 0 . Based on the programmed angle the servo motor rotates the flipping plates to flip the Dosa to its unbaked side. A shaking action is given to the flipping plate by the servo motor inorder to make sure that Dosa is not sticking on to the flipping plate. Now the baking time is again taken from control knob $\mathrm{K}_{2}$. After the Dosa is baked to the assigned time, the sliding arm travels from left extreme end to right extreme end and slides the Dosa again to the flipping plate. Again, by the action of both DC motors $M_{2}$ and $M_{3}$, the flipping plate arms move upwards and the servo motor maintains the horizontal position of the flipping plate. After the flipping plate arms reach vertical direction $\left(S_{5}, S_{6}=0,0\right)$, the servo motor rotates in the opposite direction and flips the fully baked Dosa on to the serving plate [3].

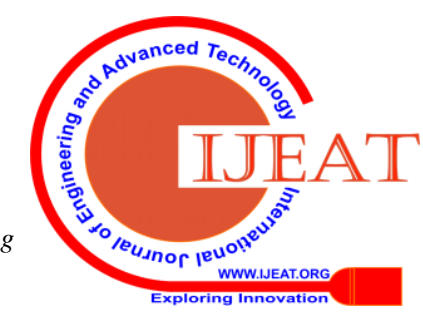




\section{Design and Fabrication of Automatic Dosa Maker}

\section{CALCULATIONS}

The Dosa batter used here is of 3:1 ratio of rice and black gram respectively. The batter density was calculated with the help of a cylinder with known diameter and height. The batter was weighed by using a weighing machine.

We know that,

Density $=$ Mass/Volume

Mass of volume taken for calculation $=165 \mathrm{~g}$

Volume of the cylinder $=176 \mathrm{~cm}^{3}$

Density $=165 / 176$

$$
=0.9375 \mathrm{~g} / \mathrm{cm}^{3}
$$

\section{Flow rate of batter}

The weight of Dosa when solenoid valve opened for 3 seconds $=110 \mathrm{~g}$

Therefore the flow rate of dosa is $27.5 \mathrm{~g} / \mathrm{s}$.

\begin{tabular}{|l|l|l|}
\hline SL NO. & QUANTITY MEASURED & VALUE \\
\hline 1 & Density & $0.9375 \mathrm{~g} / \mathrm{cm}^{3}$ \\
\hline 2 & Weight of 1 Dosa & $110 \mathrm{~g}$ \\
\hline 3 & Flow rate of batter & $27.5 \mathrm{~g} / \mathrm{s}$ \\
\hline
\end{tabular}

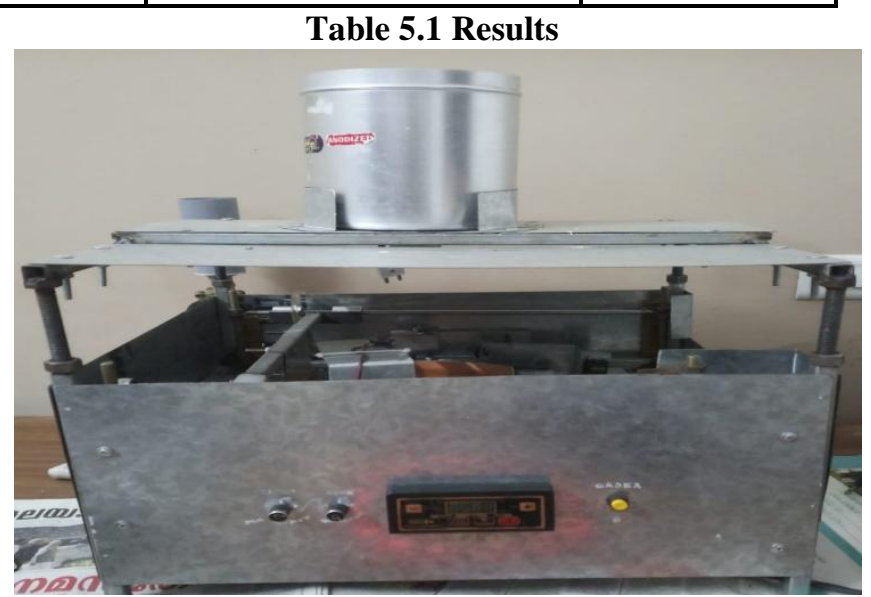

Fig 5.1 Fabricated Machine

\section{TESTING}

In order to check the working of machinery, the whole Dosa making sequence of the machine is operated using the batter with following properties. The Dosa batter used here is of $0.9375 \mathrm{~g} / \mathrm{cm}^{3}$ density and consists of rice and black gram in 3:1 ratio respectively. Oil is wiped on top of the pan by the sliding arm, to and fro motion of the sliding arm takes 14 seconds. The solenoid valve remains open for 3 seconds and 110 gram of batter is poured into the nonstick pan in 3 seconds. Each side of the Dosa is baked for 2 minutes at 1200 Fahrenheit. The flipping action takes 12 seconds to flip the Dosa to the pan and 2 seconds to flip the Dosa to the serving plate. The machine is found to have an output rate of 1 Dosa per 4 minutes 45 seconds at 1200 Fahrenheit.

\section{MERITS}

- The Dosa Maker is a light weighted machine. It is portable.

- Since it runs on electric current it does not have major impacts on the environment.
- $\quad$ The storage container could be separated and cleaned, thus improving hygiene.

- The handling of machine is safe, as they run on electricity

- There will be no human interference during the operational cycle.

- The temperature and flow rate of batter can be adjusted.

- Perfect round Dosa can be obtained.

\section{FUTURE SCOPE}

The main objective of this project was to design and fabricate a fully functional automated Dosa making machine, which bakes both the sides of the Dosa. For further development, the product could be redesigned to become more compact, lighter and cheaper - the outer sheet metal body of the machine could be replaced by moulded plastic covering. In future, for mass production - the number of Dosas could be increased by increasing the number of solenoid valves connected to the batter storage container. The user interface could be improved by using android apps - for ordering Dosas, to track time required to deliver the order and for e - payment. The machine could be designed to produce different types of Dosas like Masala Dosa, Plain Dosa, Set Dosa, Cheese Dosa, Adai Dosa etc simultaneously.

\section{RESULT AND DISCUSSION}

In the final testing of the prototype it is found out that the prototype has an output of 1 Dosa per 4 minutes 45 seconds at 1200 Fahrenheit. A Dosa of 110 gram having a diameter in between 15 to $17 \mathrm{~cm}$ is obtained as output on the serving plate. The only concern is that since both the electrical control unit and the induction cooktop are close in proximity, the cooling fan provided may not be enough to keep lower temperature at the cabin where Arduino, circuit boards and SMPS are placed.

\section{CONCLUSION}

The main objective of this work is to design and fabricate a fully functional automated Dosa making machine which bakes both the sides of the Dosa without any human intervention during its cycle of operation. In this work electric power is used because of its convenience in regulating temperature, safe working conditions and eco friendliness. Through testing and experimentation it is found that the fabricated Automatic Dosa Maker machine could give an output of 1 Dosa per 4 minutes 45 seconds at 1200 Fahrenheit. The diameter and weight of the Dosa could be varied by changing the time for which solenoid valve remains open. The output rate could be increased by using higher temperature in the pan or by using more number of solenoid valves. The Automatic Dosa making machine could be used in hotels, restaurants, take away counters and drive throughs. This works provides better understanding of material selection, manufacturing design and different manufacturing methods involved in similar fabrication processes.

Published By:

Blue Eyes Intelligence Engineering

\& Sciences Publication

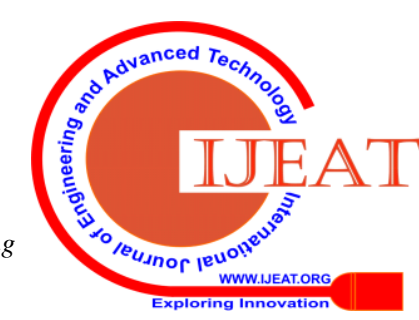




\section{REFERENCES}

1. Devasena Kannan, Ramachandran Chelliah, Emilivinoly Rajamanickam, Raman Srinivasan Venkitraman and Usha Antony, "Fermented Batter Characteristics in Relation with Sensory Properties of Idli", Croatian Journal of Food Technology, Biotechnology and Nutrition 10 (1-2), 37-43, 2015.

2. Rakshitha M.G, Mr.Madan G, Dr.K.R Prakash and Mr.Shivaraj C.S , "Design and Development Automated Food Maker", International Research Journal of Engineering and Technology (IRJET), Volume: 05, Issue:06, 2019

3. K.S Shaji, H.S.Lohith and ChiranjithBarui, "Design and Development of an Automatic Dosa Maker for Indian Households" MSRUASSASTech Journal Volume:15, Issue:1, 2018.

4. Shubham Sanjeev Jadav,'Design and Manufacturing of Steamer for Production of Idli". School of agriculture Lovely professional university Phagwara May, 2018.

5. Praise Sabu, Sreerag M.P, Sukesh P.P, Toney Varghese and Vaishak K Kurup, "Design and Development of Automated Appam Maker", International Journal for Innovative Research in Science \& Technology (IJIRST) Volume:3, Issue:11, 2017.

6. Mr.D.Meganathan, J.Rajasekar, V.PraveenKumar, S.Rajesh, S.Umasankar, M.S.Prakash, N.Saravanan,P.J.MoneshRaj and Sundar, Tejkiran, "Automatic Dosa Making Machine", International Journal of Research Culture Society (IJRCS), Volume:2, Issue:4, 2018.

7. Mr. Kaviraj.N, "Automatic Vegetable Curry Maker (AVC-MAKER)", International Journal of Engineering Sciences \& Research Technology (IJESRT), 2017.

8. Mr.Amit Kumar,Amit Prakash, Priyanka Datta, Rajesh Kumar and Anant Gopal Sharma, "Automatic Cooking Machine Using Arduino", International Journal of Recent Technology and Engineering (IJRTE), Volume:8, Issue:2, 2019.

9. https://cooking.stackexchange.com/questions/16639/how-to-fermentdosa-batter

10. https://www.nutritionix.com/food/dosa

\section{AUTHORS PROFILE}

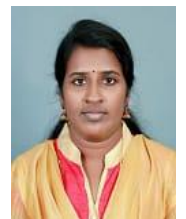

Mrs.BINDU.S.S was a Research Fellow of Kerala State Council for Science Technology and Environment (KSCSTE), Trivandrum, Kerala. She completed her Bachelors degree and Masters Degrees in Mechanical Engineering from University of Kerala. She submitted her Ph.D Thesis in Cryogenics to the University of Kerala. Now she is working as an Associate Professor in the department of Mechanical Engineering of Rajadhani Institute of Engineering and Technology, Thiruvananthapuram. Her research areas include Computational Fluid Dynamics, Cryogenics and Space technology. She is a permanent member of Indian Cryogenic Council. She has to her credit a large number of publications in international journals and conferences.

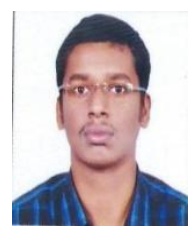

AKASH.V.M, Undergraduate student of Department of Mechanical Engineering in Rajadhani Institute of Engineering And Technology, Thiruvananthapuram. I have joined SAE INDIA as a student member in 2017. I have participated in the SAE BAJA competition conducted by SAE INDIA and Mahindra in July, 2019 and qualified the virtual BAJA.

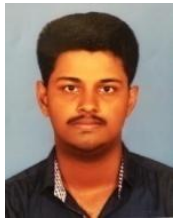

AKHIL.S, Undergraduate student of Department of Mechanical Engineering in Rajadhani Institute of Engineering And Technology, Thiruvananthapuram. I have joined SAE INDIA as a student member in 2017. I have participated in the SAE BAJA competition conducted by SAE INDIA and Mahindra in July, 2019 and qualified the virtual BAJA.

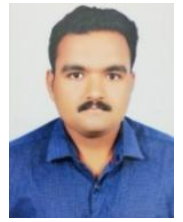

AJAY KRISHNA, Undergraduate student of Department of Mechanical Engineering in Rajadhani Institute of Engineering And Technology, Thiruvananthapuram. I have joined SAE INDIA as a student member in 2017. I have participated in the SAE BAJA competition conducted by SAE INDIA and Mahindra in July, 2019 and qualified the virtual BAJA.

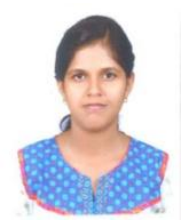

DHANUSHMA PRATHAP, Undergraduate student of Department of Mechanical Engineering in Rajadhani Institute of Engineering And Technology, Thiruvananthapuram. I have joined SAE INDIA as a student member in 2017. I have participated in the SAE BAJA competition conducted by SAE INDIA and Mahindra in July, 2019 and qualified the virtual BAJA.

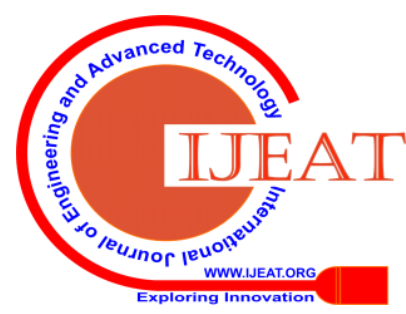

